\title{
Investigation of Corrosion Inhibition Efficiency of Some Synthesized Water Soluble Terpolymers on N-80 Steel in HCl, $\mathrm{NaCl}$ and Simulated Oil Well Water
}

\author{
R. Geethanjali ${ }^{*}$ and S. Subhashini \\ Department of Chemistry, Avinashilingam Institute for Home Science and Higher Education for \\ Women, Coimbatore, India
}

Received 26 March 2015; 23 April 2015

\begin{abstract}
Five different water soluble terpolymers, namely polyvinyl alcohol-g-poly(acrylamidevinylsulfonate), polyvinyl alcohol-g-poly(acrylic acid-vinylsulfonate), polyvinyl alcohol-g-poly(acrylamide-vinyl benzene sulfonate), polyvinyl alcohol-g-poly(acrylic acid-vinyl benzene sulfonate) and polyvinyl alcohol-g-poly(vinylsulfonate-vinyl benzene sulfonate), have been designed, developed and tested for their efficacy to control N-80 steel corrosion in $10 \% \mathrm{HCl}, 3.5 \% \mathrm{NaCl}$ and simulated well water. The terpolymer characterization was carried out by FTIR. The inhibitors were tested by potentiodynamic and impedance techniques. The inhibitors were also tested in static and dynamic conditions at $55 \pm 5{ }^{\circ} \mathrm{C}$, for 6 hours immersion period by weight loss method. Acrylamide terpolymers rendered the best inhibition efficiency in all the studied systems. The results provided a preliminary validation of the inhibitor such that they can be optimised and used for corrosion in oil and gas industries.
\end{abstract}

Keywords: $\mathrm{N}-80$ steel, $\mathrm{HCl}, \mathrm{NaCl}$, Simulated well water, Dynamic Wheel test, Polyvinyl alcohol, Polyacrylamide, Polyacrylic acid, Vinyl sulphonate, p-vinyl benzene sulphonate.

\section{Introduction}

As most of the oil field operations are carried out in aggressive environments, the spell of corrosion is inevitable. Corrosion problems occur in the petroleum industry in at least three general areas: (1) production, (2) transportation and storage, and (3) refinery operations. Surface pipelines, downhole tubing, pressure vessels, and storage tanks in oil and gas production are subject to

\footnotetext{
* Corresponding author. E-mail address: anjalirajj@gmail.com
} 
internal corrosion by water, which is enhanced by the presence of carbon dioxide (sweet corrosion) and hydrogen sulphide (sour corrosion) in the gas phase. Acidization is a process of combination of hydraulic fracturing combined with matrix acidizing [1]. Scale removal of oil well reservoirs are carried out with 10$15 \% \mathrm{HCl}$ at temperatures up to $60{ }^{\circ} \mathrm{C}$ in order to remove carbonated minerals and iron oxides [2]. The well reservoirs mainly contain carbon dioxide, hydrogen sulfide, oxygen (dissolved), chlorides, bicarbonates, sulfates and sulfur, etc., which are well known corrodants. Further, oil well stimulation usually employs aggressive acid solutions like $\mathrm{HCl}, \mathrm{HF}$, acetic, formic, sulfamic and chloroacetic acids, depending on the nature of the rocks present [3]. For most of the cases hydrochloric acid founds to be effective in dissolving the plugging of the oil wells, because it forms metal chlorides which dissolve rapidly when compared to phosphates, sulphates and nitrates. N80, X-60 and API X65 type steel are used for the casing and tubing materials of the oil wells which are subjected to severe internal corrosion. The internal corrosion mitigation is costly because of very difficult inspection and mitigation methods. So use of inhibitors could be an efficient way to combat and tame corrosion internally. The use of corrosionresistant alloys is currently limited by the high initial capital investment associated with these materials. The development of lower alloy, less expensive corrosion-resistant alloys, particularly for offshore applications, would increase reliability of the major arteries. This development will be inexorably linked to the commodity price of oil.

Several organic and inorganic inhibitors are used for corrosion mitigation studies, for example, chromates, phosphates, acetylenic alcohols, aromatic $\alpha, \beta$ unsaturated aldehydes, $\alpha$-alkenyl phenones, nitrogen and sulfur containing heterocyclic compounds, quaternary ammonium salts and condensation products of carbonyls and amines [4-11]. Acetylenic alcohols were preferred inhibitors for acid matrixization but their use is limited because they produce toxic gases during the treatment and contaminates the soil and water where they have been used. Since most of the organic and inorganic inhibitors are insoluble in aqueous solutions, they are dissolved in organic solvents. Concerns of environmental safety issues usually disclaim this practice, and hence corrosion/scale inhibitors soluble in aqueous solutions are highly preferred. Hence water soluble polymeric corrosion inhibitors can be the best alternative to fix the issue. Very few reports are available in the literature on water soluble polymers as corrosion inhibitors for oil well tubing and casing material in harsh environments. Finsagar et al. studied the effectiveness of polyethyleneimines of different molecular weights as corrosion inhibitors for AISI 430 [12] and ASTM 420 [13] stainless steel in nearneutral chloride media. Gao et al. [14] reported that the high inhibition efficiency of some acetylenic alcohols with a-alkenylphenones and $\alpha, \beta$ - unsaturated aldehydes is due to the surface polymerization during acid environmentally benign, easily degradable and suitable for use in both acidic and neutral media. Polymers have large surface area, thereby assuring uniform adsorption on the metal surface by forming an intact protective film. Moreover water soluble polymers of the present study are composed of polyvinyl alcohol, polyacrylamide, polyacrylic acid, polyvinyl sulfonate and polyvinyl benzene 
sulfonate, which are known eco-friendly and bio compatible polymers. This paper describes an attempt made to evaluate the inhibitory action of the synthesized water dispersible grafted terpolymers as inhibitor for $\mathrm{N}-80$ casing material under various harsh environments like $\mathrm{HCl}, \mathrm{NaCl}$ and simulated oil well water.

Table 1. Feed ratio of monomers used for synthesizing grafted terpolymers.

\begin{tabular}{|l|c|}
\hline Terpolymer product & Feed ratio of monomer $(\mathbf{g})$ \\
\hline $\begin{array}{l}\text { PVA-AAm-VSA } \\
\text { PVA-AA-VSA }\end{array}$ & $2.5: 1: 1.5$ \\
\hline $\begin{array}{l}\text { PVA-AAm-PVBS } \\
\text { PVA-AA-PVBS } \\
\text { PVA-VSA-PVBS }\end{array}$ & $2.5: 1: 0.5$ \\
\hline
\end{tabular}

\section{Experimental}

Synthesis

The feed ratio of reactants for synthesis of each grafted terpolymer is listed in Table 1. PVA (2.5 g; mol wt. 1,40,000), acrylamide/acrylic acid (1 g), and vinyl sulfonic acid sodium salt (1.5 g)/ p-vinyl sulfonic acid sodium salt (0.5 g) were dissolved in $80 \mathrm{~mL}$ of water. The whole reaction mixture was purged with nitrogen gas for half-an-hour. $10 \mathrm{~mL}$ of sodium dodecyl sulfonate solution $(0.03$ g) were mixed into the reaction solution. The redox initiator pair potassium persulfate and $0.01 \mathrm{M}$ of TEMED was added slowly to the reaction mixture in order to initiate the polymerization reaction. The reaction was allowed to continue for 3 hours. After 3 hours, the reaction mixture was added to five-fold volume of acetone and the final product was precipitated. The products were washed with acetone/water mixture to remove the unreacted monomers and homopolymers, dried under vacuum for 24 hours and utilized for further studies. The terpolymer formation was confirmed from the FTIR characteristic vibrations (Table 2).

\section{Materials}

Rectangular steel coupons with the size of $5 \times 1 \times 0.3 \mathrm{~cm}$ were cut from the N-80 steel casings (kindly supplied by ONGC) for static and dynamic weight loss studies, and with the size of $1.0 \times 1.0 \times 0.3 \mathrm{~cm}$ electrode for electrochemical studies. N-80 steel used for the study contains the following composition: $\mathrm{C}$ $(0.31 \%), \mathrm{S}(0.008 \%), \mathrm{P}(0.010 \%), \mathrm{Si}(0.19 \%), \mathrm{Mn}(0.92 \%), \mathrm{Cr}(0.20 \%)$, and remaining of $\mathrm{Fe}$. Corrosive solutions were $10 \% \mathrm{HCl}, 3.5 \% \mathrm{NaCl}$ and simulated oil well water prepared according to the procedure described by Azghandi et al. 2012 [15]: 3.5 wt. $\% \mathrm{NaCl}, 0.305$ wt. \% calcium chloride and 0.186 wt. \% magnesium chloride hexahydrate were dissolved in water. $100 \mathrm{ppm}$ of $\mathrm{H}_{2} \mathrm{~S}$ were produced in the solution in-situ by adding $0.067 \mathrm{~g}$ of $\mathrm{Na}_{2} \mathrm{~S}$ and $0.4 \mathrm{~mL}$ of $\mathrm{HCl}$ just before closing the bottles for studies. All the solutions were prepared with distilled water. The inhibitor stock solutions were prepared by dissolving 3 wt. $\%$ of each terpolymer in distilled water. 
Table 2. FTIR characteristic vibrations observed in grafted terpolymers.

\begin{tabular}{|l|c|c|c|c|c|}
\hline Type of vibrations & $\begin{array}{c}\text { PVA-AAm-VSA } \\
\left(\mathrm{cm}^{-1}\right)\end{array}$ & $\begin{array}{c}\text { PVA-AAm-VSA } \\
\left(\mathrm{cm}^{-1}\right)\end{array}$ & $\begin{array}{c}\text { PVA-AAm-PVBS } \\
\left(\mathrm{cm}^{-1}\right)\end{array}$ & $\begin{array}{c}\text { PVA-AA-PVBS } \\
\left(\mathrm{cm}^{-1}\right)\end{array}$ & $\begin{array}{c}\text { PVA-VSA-PVBS } \\
\left(\mathrm{cm}^{-1}\right)\end{array}$ \\
\hline $\begin{array}{l}\text { OH str. inter and intra } \\
\text { molecular hydrogen } \\
\text { bonding }\end{array}$ & $3000-3700$ & $3000-3700$ & $3000-3700$ & $3000-3700$ & $3000-3600$ \\
\hline Alkyl-CH str. & $2941(\mathrm{w})$ & 2941 & - & - & - \\
\hline Ar. CH str. & & & 2923,2842 & 2923,2842 & 2985 \\
\hline Amide I C=O & 1653 & - & 1644 & & 1697 \\
\hline C=O str. & - & 1661 & - & 1644 & 1421 \\
\hline $\begin{array}{l}\text { C-O-H bending/ } \\
\text { C-H bending vibrations }\end{array}$ & 1429 & 1437 & 1438 & 1456 & 1295 \\
\hline Amide III C-N & 1367 & - & 1376 & & 1170,1054 \\
\hline C-O str. & 1268 & 1260 & 1259 & 1260 & 1179, \\
\hline $\begin{array}{l}\text { Asymmetric and } \\
\text { symmetric S=O str. }\end{array}$ & $1153-1089(\mathrm{w})$ & $1106-1044(\mathrm{~s})$ & $1197-1098(\mathrm{w})$ & $1009(\mathrm{~s})$ & 1009 \\
\hline $\begin{array}{l}\text { Out-of-plane bending } \\
\text { vibrations of p-substituted } \\
\text { ar.unit }\end{array}$ & 1268 & - & 660,446 & 678,455 & 674,804 \\
\hline
\end{tabular}

\section{Electrochemical studies}

The electrochemical measurements were carried out using a three-electrode cell assembly comprising of a saturated calomel electrode (reference), a platinum electrode (counter) and N-80 metal coupon as working electrode. The metallic coupons were dipped in three different media at $55 \pm 5{ }^{\circ} \mathrm{C}$. Before each experiment, open circuit potential was measured for $1 / 2$ hour in order to reach a steady state. Potentiodynamic polarisation was performed with a sweep rate of 2 $\mathrm{mV} / \mathrm{s}$ in the range of $-0.1 \mathrm{~V}$ to $-1 \mathrm{~V}$ with respect to the corrosion potential. Various corrosion kinetic parameters such as corrosion current density ( $\left.\mathrm{I}_{\text {corr }}\right)$, corrosion potential ( $\left.\mathrm{E}_{\mathrm{corr}}\right)$, anodic and cathodic Tafel slopes ( $\mathrm{B}_{\mathrm{a}}$ and $\mathrm{B}_{\mathrm{c}}$ ) were obtained. Corrosion current density was measured from the intersection point obtained by the extrapolation of Tafel lines.

The impedance measurement was performed using AC signals with $10 \mathrm{mV}$ amplitude for the frequency range from $100 \mathrm{kHz}$ to $0.01 \mathrm{~Hz}$ at corrosion potential. Solatron electrochemical analyzer model (1280 B) interfaced with IBM computer along with Corrware and $\mathrm{Z}$ plot softwares were used for data acquisition and analysis. EIS Analyzer software was used to fit the experimental results of EIS measurements using the appropriate equivalent circuit.

The inhibition efficiency was calculated from corrosion current $\mathrm{I}_{\text {corr, }}$ and $\mathrm{R}_{c t}$ using the following relations.

$$
\begin{aligned}
& I E(\%)=\frac{I_{c o r r}^{\circ}-I_{c o r r}}{I_{\text {corr }}^{o}} X 100 \\
& I E(\%)=\frac{R_{c t}-R_{c t}^{\circ}}{R_{c t}} \times 100
\end{aligned}
$$

$\mathrm{I}^{\mathrm{O}}$ corr and $\mathrm{I}_{\text {corr }}$ are the corrosion current densities of uninhibited and inhibited solutions respectively. $R_{c t}$ and $R_{c t}^{o}$ are the charge transfer resistances of inhibited and uninhibited solutions, respectively. 


\section{Gravimetric tests}

Before each test, N-80 steel coupons were degreased using xylene, followed by cleaning with water and acetone. Then the coupons were wiped using isopropanol to get a glassy finish. The cleaned metals were dried by wiping with a soft tissue and stored in a desiccator for an hour. All the tests were performed based on the ASTM standards G1, G170, NACE ID 182, item no. 24007 \& ONGC corporate specification for oil field chemicals.

\section{Static tests}

Corrosion rates were evaluated by exposing N-80 steel coupons to preheated 10 $\% \mathrm{HCl} / 3.5 \% \mathrm{NaCl} / \mathrm{simulated}$ well water for 6 hours at atmospheric pressure without and with $0.6 \mathrm{wt} . \%$ of inhibitors. The temperature was maintained at $55 \pm 5$ ${ }^{\circ} \mathrm{C}$.

\section{Dynamic tests}

Similarly, the polymeric inhibitors were tested under dynamic conditions. Dynamic tests were performed using the Wheel test apparatus in R\&D laboratory of ONGC, Mumbai. Wheel test is widely used for assessment of the inhibitor film persistency during corrosion studies. The test solutions were filled in capped bottles, in which the weighed metal coupons were tied to the cap using a nylon thread. The bottles were placed tightly in the compartments of wheel test apparatus and the wheel was rotated using a motor at $55 \pm 5{ }^{\circ} \mathrm{C}$ for 6 hours at rotation speed of $25 \mathrm{rpm}$. After each test, the coupons were dipped in Clark's solution and rinsed with water thoroughly to remove any corrosion deposits. A final acetone wash was given before reweighing.

\section{Results and discussion}

\section{Potentiodynamic polarisation}

The anodic and cathodic polarisation curves for $\mathrm{N}-80$ steel in absence and presence of 0.6 wt.\% of each inhibitor in $\mathrm{HCl}, 3.5 \% \mathrm{NaCl}$ and simulated petroleum corrosive solution are shown in Figs. 1, 2 and 3. The intersection point of Tafel regions gives the corrosion current density $\left(\mathrm{I}_{\text {corr }}\right)$. The obtained polarisation parameters $b_{a}, b_{c}, I_{c o r r}$ and $E_{c o r r}$ in the different media are given in Tables 3-5.

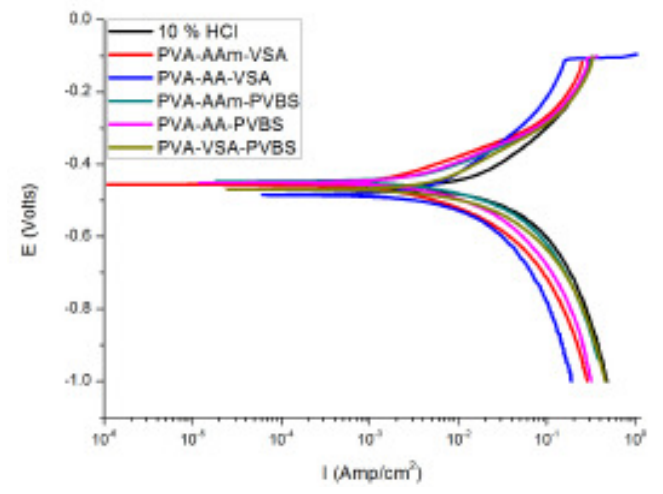

Figure 1. Tafel plot for $0.6 \mathrm{wt} . \%$ of terpolymers in $10 \% \mathrm{HCl}$. 
In the polarisation curves obtained from $\mathrm{HCl}$ medium, both the anodic and cathodic regions are shifted to lower corrosion current density region on inhibitor addition. This indicates that terpolymer compounds are adsorbed on the metal surface rendering inhibition effect. The Tafel curves are quite parallel in nature indicating that the hydrogen evolution is activation controlled and the mechanism is not altered after addition of the inhibitor [16]. The variation in the Tafel slopes is an indication of change in reaction kinetics. The addition of inhibitor diminishes the Tafel slope values when compared to that of blank $\mathrm{HCl}$. This is because when the anodic and cathodic regions are polarized, the reaction kinetics speed up in inhibited solution when compared to that of blank. Since the inhibitors in $\mathrm{HCl}$ medium influence both the cathodic and anodic reactions, the inhibitors can be concluded to be of mixed-type [17,18]. The change in the corrosion potential is less than $85 \mathrm{mV}$ which again proves mixed type inhibition [19]. It can also be explained that the inhibitor basically reduces the surface area prone to corrosion reaction and neither alters the reaction process of anode nor cathode. The inspection of the results in the Table indicates that terpolymers decrease the corrosion current density in the studied range of concentrations providing a maximum inhibition in the range of $80-92 \%$ for $0.6 \mathrm{wt}$. $\%$ concentration of the respective inhibitors. A maximum IE of $92 \%$ and $90 \%$ is obtained for PVA-AAm-PVBS and PVA-AAm-VSA respectively, followed by PVA-AA-PVBS, PVA-AA-VSA and PVA-VSA-PVBS.

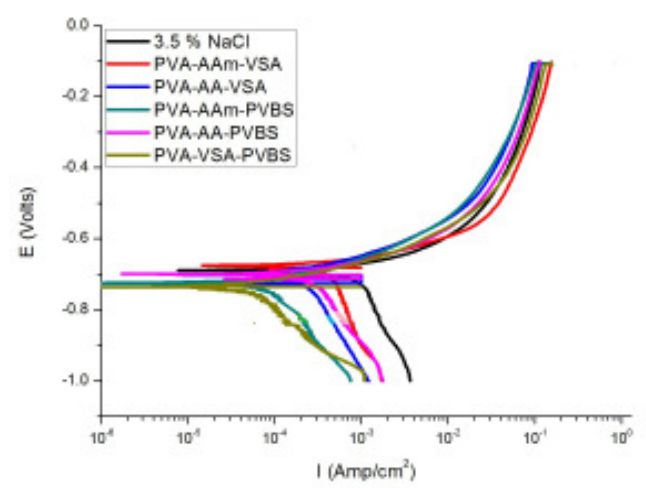

Figure 2. Tafel plot for $0.6 \mathrm{wt} . \%$ of terpolymers in $3.5 \% \mathrm{NaCl}$.

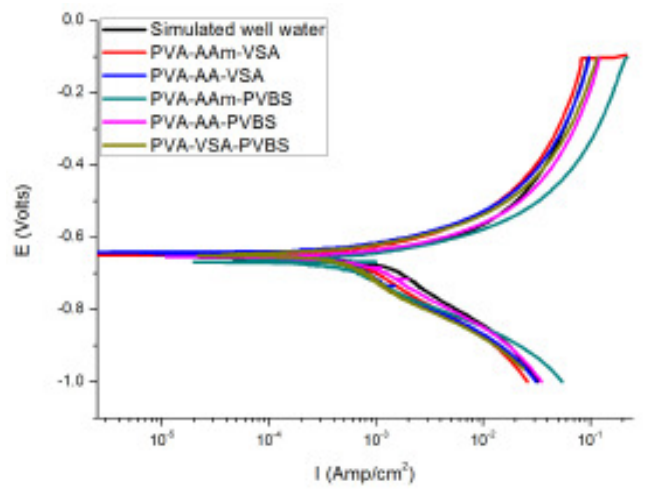

Figure 3. Tafel plot for 0.6 wt.\% of terpolymers in simulated oil well water. 
Table 3: Potentiodynamic parameters obtained for $\mathrm{N} 80$ steel in $\mathrm{HCl}$.

\begin{tabular}{|c|c|c|c|c|c|c|}
\hline $\mathrm{HCl}$ & $\begin{array}{l}\text { Conc. } \\
\text { Wt.\% }\end{array}$ & $\begin{array}{c}\mathrm{b}_{\mathrm{a}} \\
\mathrm{mV} / \mathrm{dec}\end{array}$ & $\begin{array}{c}\mathbf{b}_{\mathrm{c}} \\
\mathrm{mV} / \mathrm{dec}\end{array}$ & $\begin{array}{c}\text { Io } \\
\left(\mathrm{mA} \mathrm{cm}^{-2}\right)\end{array}$ & $\begin{array}{l}\text { Io } \\
\%\end{array}$ & $\begin{array}{c}\text { Eo } \\
(\mathrm{V}(\mathrm{SCE}))\end{array}$ \\
\hline Blank & & 235.25 & 165.41 & 0.0350 & & -462.2 \\
\hline \multirow[t]{3}{*}{ PVA-AAm-VSA } & 0.09 & 232.47 & 217.42 & 0.0146 & 58.42 & -455.9 \\
\hline & 0.45 & 168.75 & 177.66 & 0.0076 & 78.40 & -447.8 \\
\hline & 0.6 & 147.68 & 160.03 & 0.0033 & 90.62 & -471.3 \\
\hline \multirow[t]{3}{*}{ PVA-AAm-PVBS } & 0.09 & 217.52 & 221.37 & 0.0116 & 66.97 & -462.3 \\
\hline & 0.45 & 169.82 & 175.71 & 0.0078 & 77.58 & -458.4 \\
\hline & 0.6 & 127.28 & 144.37 & 0.0026 & 92.51 & -455.8 \\
\hline \multirow[t]{3}{*}{ PVA-AA-VSA } & 0.09 & 306.28 & 269.48 & 0.0118 & 66.27 & -484.8 \\
\hline & 0.45 & 153.16 & 168.37 & 0.0065 & 81.39 & -456.1 \\
\hline & 0.6 & 165.85 & 164.71 & 0.0057 & 83.59 & -464.8 \\
\hline \multirow[t]{3}{*}{ PVA-AA-PVBS } & 0.09 & 184.73 & 188.18 & 0.0076 & 78.17 & -452.2 \\
\hline & 0.45 & 157.92 & 170.23 & 0.0059 & 83.12 & -454.4 \\
\hline & 0.6 & 133.08 & 150.1 & 0.0037 & 89.36 & -451.7 \\
\hline \multirow[t]{3}{*}{ PVA-VSA-PVBS } & 0.09 & 297.77 & 245.72 & 0.0227 & 35.23 & -507.6 \\
\hline & 0.45 & 222.05 & 196.01 & 0.0130 & 62.83 & -480.7 \\
\hline & 0.6 & 206.22 & 186.44 & 0.0065 & 81.35 & -469.3 \\
\hline
\end{tabular}

Table 4. Potentiodynamic parameters for $\mathrm{N} 80$ steel in $\mathrm{NaCl}$ medium.

\begin{tabular}{|c|c|c|c|c|c|}
\hline $\mathrm{NaCl}$ & $\begin{array}{l}\text { Conc. } \\
\text { Wt.\% }\end{array}$ & $\begin{array}{c}\mathbf{b}_{\mathrm{a}} \\
\mathrm{mV} / \mathrm{dec}\end{array}$ & $\begin{array}{c}\text { Io } \\
\left(\mathrm{mA} \mathrm{cm}^{-2}\right)\end{array}$ & $\begin{array}{l}\text { Io } \\
\%\end{array}$ & $\begin{array}{c}\text { Eo } \\
(\mathrm{V}(\mathrm{SCE}))\end{array}$ \\
\hline Blank & & 31.11 & 0.00074 & & -676.7 \\
\hline \multirow[t]{3}{*}{ PVA-AAm-VSA } & 0.09 & 50.22 & 0.00034 & 54.054 & -716.5 \\
\hline & 0.45 & 52.55 & 0.00022 & 70.270 & -725.3 \\
\hline & 0.6 & 49.99 & 0.00012 & 83.784 & -705.1 \\
\hline \multirow[t]{3}{*}{ PVA-AAm-PVBS } & 0.09 & 48.25 & 0.00036 & 51.351 & -705.0 \\
\hline & 0.45 & 50.24 & 0.00019 & 74.324 & -697.6 \\
\hline & 0.6 & 49.42 & 0.00006 & 91.892 & -788.8 \\
\hline \multirow[t]{3}{*}{ PVA-AA-VSA } & 0.09 & 58.26 & 0.00034 & 54.054 & -693.1 \\
\hline & 0.45 & 54.65 & 0.0003 & 59.459 & -456.5 \\
\hline & 0.6 & 52.02 & 0.00018 & 75.676 & -702.1 \\
\hline \multirow[t]{3}{*}{ PVA-AA-PVBS } & 0.09 & 32.24 & 0.00027 & 63.514 & -698.6 \\
\hline & 0.45 & 32.25 & 0.00025 & 66.216 & -706.1 \\
\hline & 0.6 & 31.61 & 0.00022 & 70.270 & -700.1 \\
\hline \multirow[t]{3}{*}{ PVA-VSA-PVBS } & 0.09 & 40.25 & 0.00034 & 54.054 & -734.8 \\
\hline & 0.45 & 42.25 & 0.00036 & 51.351 & -732.4 \\
\hline & 0.6 & 45.781 & 0.0002 & 72.973 & -734.8 \\
\hline
\end{tabular}


Table 5. Potentiodynamic parameters for N80 steel in simulated well water medium.

\begin{tabular}{|c|c|c|c|c|c|c|}
\hline Simulated well water & $\begin{array}{l}\text { Conc. } \\
\text { Wt.\% }\end{array}$ & $\begin{array}{c}b_{a} \\
\mathrm{mV} / \mathrm{dec}\end{array}$ & $\begin{array}{c}\mathbf{b}_{\mathrm{c}} \\
\mathrm{mV} / \mathrm{dec}\end{array}$ & $\begin{array}{c}\text { Io } \\
\left(\mathrm{mA} \mathrm{cm} \mathbf{~ c m}^{-2}\right)\end{array}$ & $\begin{array}{l}\text { Io } \\
\text { \% }\end{array}$ & $\begin{array}{c}\text { Eo } \\
(\mathbf{V}(\mathbf{S C E}))\end{array}$ \\
\hline Blank & & 78.137 & 65.567 & 0.0098 & & -807.1 \\
\hline \multirow[t]{3}{*}{ PVA-AAm-VSA } & 0.09 & 120.66 & 179.38 & 0.0011 & 88.78 & -685.9 \\
\hline & 0.45 & 110.22 & 153.82 & 0.0007 & 92.86 & -675.3 \\
\hline & 0.6 & 118.40 & 178.70 & 0.0008 & 91.84 & -668.5 \\
\hline \multirow[t]{3}{*}{ PVA-AAm-PVBS } & 0.09 & 155.42 & 287.15 & 0.0017 & 82.65 & -654.7 \\
\hline & 0.45 & 135.34 & 267.96 & 0.0009 & 90.82 & -649.3 \\
\hline & 0.6 & 113.11 & 167.54 & 0.0004 & 95.92 & -641.6 \\
\hline \multirow[t]{3}{*}{ PVA-AA-VSA } & 0.09 & 200.96 & 453.92 & 0.0029 & 70.41 & -636.7 \\
\hline & 0.45 & 174.56 & 350.42 & 0.0019 & 80.61 & -646.4 \\
\hline & 0.6 & 161.25 & 308.09 & 0.0013 & 86.73 & -648.5 \\
\hline \multirow[t]{3}{*}{ PVA-AA-PVBS } & 0.09 & 167.05 & 196.87 & 0.0009 & 90.82 & -685.0 \\
\hline & 0.45 & 214.04 & 132.07 & 0.0006 & 93.88 & -698.0 \\
\hline & 0.6 & 224.04 & 175.52 & 0.0004 & 95.92 & -705.2 \\
\hline \multirow[t]{3}{*}{ PVA-VSA-PVBS } & 0.09 & 216.55 & 512.10 & 0.0051 & 47.96 & -669.5 \\
\hline & 0.45 & 235.73 & 348.21 & 0.0034 & 65.31 & -632.7 \\
\hline & 0.6 & 197.84 & 394.13 & 0.0029 & 81.63 & -656.3 \\
\hline
\end{tabular}

Potentiodynamic polarisation in $3.5 \% \mathrm{NaCl}$

The polarisation curves obtained for $\mathrm{N}-80$ steel in $3.5 \% \mathrm{NaCl}$ clearly show trans-active, passive and trans-passive characteristics which is in agreement with the curves obtained for $\mathrm{NaCl}$ medium in literature [20,21]. The addition of the terpolymers makes the corrosion potential $\mathrm{E}_{\text {corr }}$ to remain constant/ shift slightly in the negative direction, simultaneously reducing both the anodic and cathodic current densities. The inhibition of both anodic and cathodic reactions along with minimal change in corrosion potential values to that of blank is an indication of change in the inhibition mechanism in neutral medium, i.e., the inhibitor's usual function of blocking active sites is changed to geometric blocking effect in the presence of the corrosion products [11]. However, since the shift in the $\mathrm{E}_{\text {corr }}$ values is not more than $85 \mathrm{mV}$, the inhibitor can be considered only as of the mixed type. As far as the Tafel slopes are considered, accurate evaluation of the Tafel slopes is not possible as the polarisation curve does not exhibit a linear Tafel region. In that case, corrosion rate can be determined by considering either anodic or cathodic region alone. In the absence of oxygen, the dominant reaction is $\mathrm{H}^{+}$ion reduction because of the high $\mathrm{H}^{+}$ion concentration. In the presence of oxygen the dominant reaction is however the oxygen reduction which is a multi electron reaction involving various intermediates. Due to the slow diffusion of oxidizing species, potentiodynamic polarisation can act to shorten the linear cathodic region. Sometimes linearity may entirely disappear, then cathodic reaction will be under combined activation and diffusion control at $\mathrm{E}_{\text {corr }}[22,23]$. Hence cathodic region cannot be considered for evaluation of corrosion current. 
So, anodic region is preferred for the evaluation of the corrosion current and Tafel slopes $\left(b_{a}\right)$ [24] and are listed in Table 4. The curvature of the anodic region can be attributed to the deposition of corrosion products.

The $\mathrm{I}_{\text {corr }}$ values are significantly reduced upon the addition of inhibitor in all cases furnishing a maximum IE in the range of 50-91 \% for $0.6 \mathrm{wt} \%$ concentration of the inhibitors. These effects could be due to the adsorption of long chains of the terpolymer inhibitor onto the metal surface thus producing a barrier film and consequently minimizing the anodic metal dissolution and cathodic hydrogen evolution. The IE calculated from the $\mathrm{I}_{\text {corr }}$ values for $0.6 \mathrm{wt} . \%$ inhibitor concentration has the following trend: PVA-AAm-PVBS $>$ PVA-AAmVSa $>$ PVA-AA-VSA $>$ PVA-VSA-PVBS $>$ PVA-AA-PVBS.

Table 6. Impedance parameters of N80 steel in $\mathrm{HCl}$ medium.

\begin{tabular}{ccccccc}
\hline & $\begin{array}{c}\text { Conc. } \\
\text { Wt. } \%\end{array}$ & $\begin{array}{c}\text { Rs/ } \\
\boldsymbol{\Omega c m}^{2}\end{array}$ & $\begin{array}{c}\mathbf{C P E} \\
\mathbf{F c m}^{2} * \mathbf{1 0}^{-\mathbf{6}}\end{array}$ & $\mathbf{N}$ & $\begin{array}{c}\text { Rct } \\
\mathbf{k} \boldsymbol{\Omega} \mathbf{c m}^{2}\end{array}$ & $\begin{array}{c}\text { IE Rct } \\
\text { \% }\end{array}$ \\
Blank & & 0.9178 & 1806 & 0.860 & 4.50 & \\
PVA-AAm-VSA & 0.09 & 1.1800 & 699 & 0.892 & 11.13 & 59.57 \\
& 0.45 & 0.7977 & 788 & 0.809 & 13.69 & 67.13 \\
& 0.6 & 0.8598 & 223 & 0.826 & 40.12 & 88.78 \\
PVA-AAm-PVBS & 0.09 & 1.2840 & 340 & 0.812 & 37.35 & 87.95 \\
& 0.45 & 1.2020 & 925 & 0.806 & 43.21 & 89.59 \\
& 0.6 & 1.9210 & 262 & 0.802 & 60.46 & 92.56 \\
PVA-AA-VSA & 0.09 & 0.6872 & 738 & 0.796 & 8.94 & 49.69 \\
& 0.45 & 0.7690 & 1369 & 0.827 & 15.15 & 70.30 \\
& 0.6 & 0.6718 & 1247 & 0.828 & 21.08 & 78.65 \\
PVA-AA-PVBS & 0.09 & 0.9074 & 506 & 0.754 & 23.16 & 80.57 \\
& 0.45 & 0.7910 & 548 & 0.807 & 23.72 & 81.03 \\
& 0.6 & 0.8114 & 444 & 0.782 & 28.40 & 84.15 \\
& & & & & & \\
PVA-VSA-PVBS & 0.09 & 1.2840 & 340 & 0.812 & 37.35 & 49.69 \\
& 0.45 & 1.2020 & 925 & 0.806 & 43.21 & 56.01 \\
& 0.6 & 1.9210 & 262 & 0.802 & 60.46 & 75.32 \\
\hline
\end{tabular}

Potentiodynamic polarisation in simulated oil well water

The polarisation curves obtained for $\mathrm{N}-80$ steel in simulated oil well water show that, the addition of the terpolymers shifts the corrosion potential $\left(\mathrm{E}_{\mathrm{corr}}\right)$ to noble directions. The presence of sulphide ions in sodium chloride medium increases the acidity of the solution due to local acidification caused by iron sulphide formation. This non-protective iron sulphide film is responsible for corrosion attack of metal in blank solution. In this case the cathodic region shows a normal Tafel behaviour because the reduction of oxygen is not a dominant reaction [25] as that occurring in $3.5 \% \mathrm{NaCl}$ medium. This shift in $\mathrm{E}_{\text {corr }}$ values is more than 85 $\mathrm{mV}$ in positive direction which indicates that the terpolymers are predominantly an anodic inhibitor. The large transition in the $\mathrm{E}_{\text {corr }}$ values is related to the active site blocking effect of the inhibitor. The anodic curve for the $\mathrm{N}-80$ steel in simulated water exhibits distinct regions, which are the active dissolution (apparent Tafel region) and the transition region. The curvature in the anodic 
branch can be attributed to the film formation. Both the Tafel slopes were enhanced with respect to blank, indicating that the inhibitors suppressed both the anodic and cathodic processes and behave as mixed-type inhibitors with predominant action on anodic areas [26]. The corrosion current densities were calculated by extrapolation of anodic and cathodic Tafel lines. From Table 6, it is evident that $\mathrm{I}_{\text {corr }}$ decreases from $0.0098 \mathrm{~mA} / \mathrm{cm}^{2}$ in blank to range of 0.004 $0.0029 \mathrm{~mA} / \mathrm{cm}^{2}$ in inhibited acid. The IE rendered by the terpolymers in simulated oil well water was found to follow the same trend as that of $\mathrm{HCl}$ medium.

\section{Impedance spectroscopy}

Fig.4-6 show the Nyquist plots for $\mathrm{N} 80$ steel in $10 \% \mathrm{HCl}, 3.5 \% \mathrm{NaCl}$ and simulated well water in the presence and absence of $0.6 \mathrm{wt} . \%$ of the PVA-AAmVSA, PVA-AA-VSA, PVA-AAm-PVBS, PVA-AA-PVBS and PVA-VSAPVBS, generated at $55 \pm 5{ }^{\circ} \mathrm{C}$. The equivalent circuit models used for fitting data are presented as inset in the respective Nyquist plots. This pure electric model can verify or rule out mechanistic models and enable the calculation of numerical values corresponding to the physical and/or chemical properties of the electrochemical system under investigation. The data acquired by fitting the equivalent circuit for all the systems are listed in Tables 6-8.

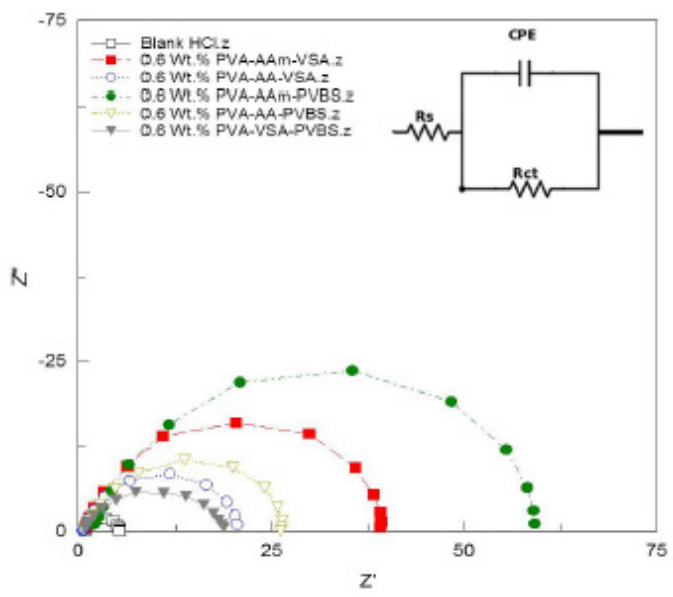

Figure 4. Nyquist plot for $0.6 \mathrm{wt} . \%$ of terpolymers in $\mathrm{HCl}$ in the absence and presence of $0.6 \mathrm{wt} . \%$ of terpolymer inhibitors.

\section{Impedance analysis in $\mathrm{HCl}$}

For iron dissolution in acid, the equivalent circuit is designed with a resistor and capacitor in parallel with each other. Three types of resistances can be taken into account: solution resistance, polarisation resistance and charge transfer resistance. Solution resistance is the ionic solution resistance which depends upon ionic concentration, type of ions, temperature and geometry of the area in which current is carried. The interface of the metal in the electrolyte is envisioned as the space that exists between array of ions on the electrode surface and array of solvated ions away from the surface. The two arrays of ions can store charge in themselves and act as a capacitor element. The capacitance thus generated is called the double layer capacitance, $\mathrm{Cdl}$. The double layer capacitor 
can also lead to a resistor providing charge transfer resistance, as the charge is transferred during the metal dissolution. The Nyquist plot for Randle's cell consisting of the above elements is always a semicircle. The solution resistance can be determined from the real axis value at the high frequency intercept. This is the intercept near the origin of the plot. The low frequency region gives us the sum of solution resistance and polarisation resistance.

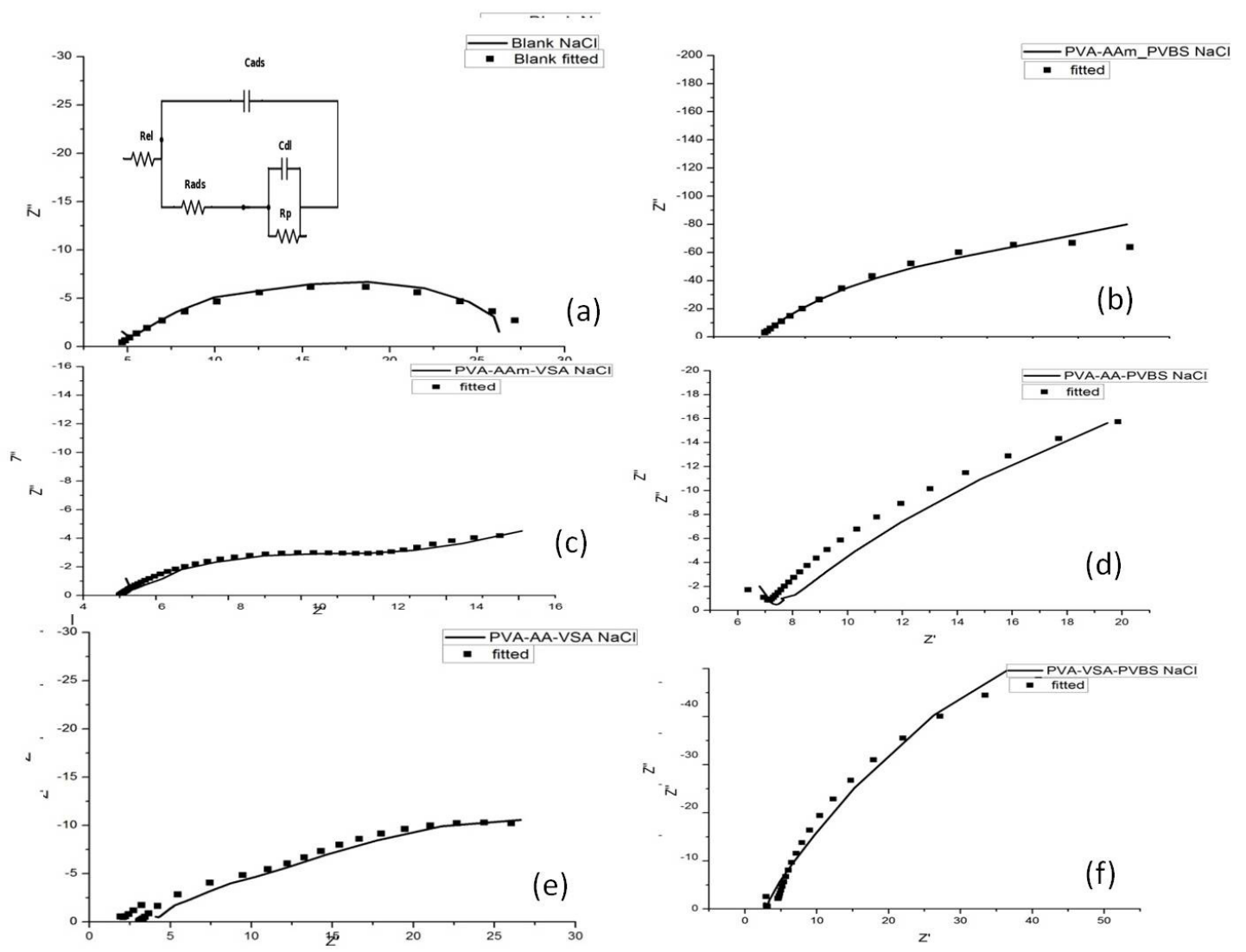

Figure 5 (a-f). Nyquist plots of $\mathrm{N}-80$ steel in $3.5 \% \mathrm{NaCl}$ in the absence and presence of $0.6 \mathrm{wt} . \%$ of terpolymer inhibitors.

Fig. 4 shows the impedance response of $0.6 \mathrm{wt} . \%$ of each inhibitor on N80 steel in $10 \% \mathrm{HCl}$. The impedance diagram consists of a single semicircle indicating a single charge transfer reaction. The shape of the semicircle is depressed in nature from high to medium frequency region which is an indication of micro-roughness and other inhomogeneties of the working electrode during the reaction [27].

Nevertheless, introduction of the inhibitors increases the diameter of the capacitive semicircle with respect to corrosion mitigating capability of the inhibitor. The values of $\mathrm{R}_{\mathrm{ct}}$ in the presence of inhibitors are higher than in their absence, indicating the formation of protective film on the metal/solution interface [28] The Cdl values were calculated at the frequency $\mathrm{f}_{\max }$, at which the imaginary component of the impedance is maximal ( $\left.Z^{\prime \prime}\right)$ by the following equation:

$$
C d l=\frac{1}{2 \pi f \max } R_{o t}
$$




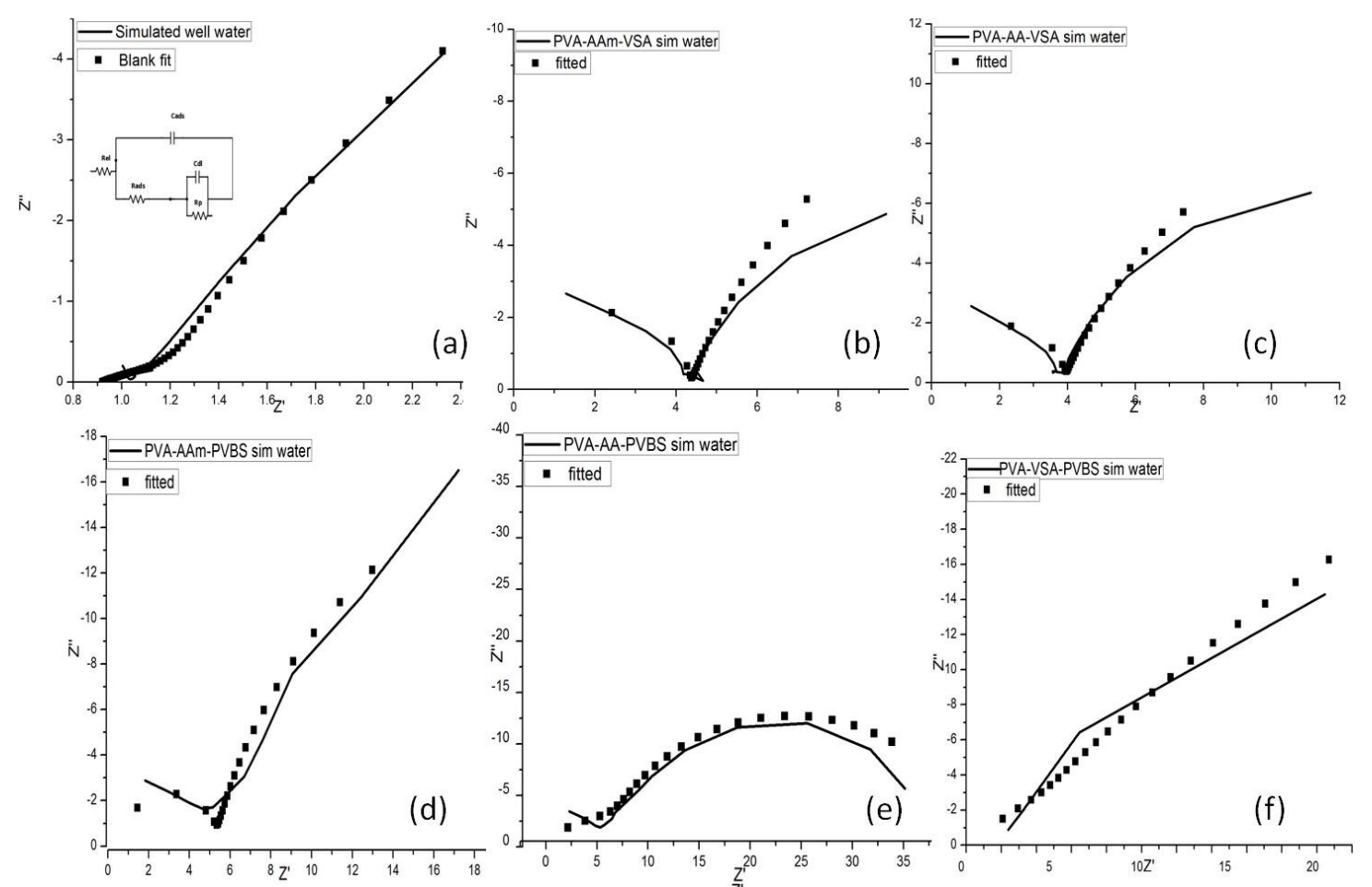

Figure 6 (a-f). Nyquist plots of N-80 steel in simulated well water in the absence and presence of $0.6 \mathrm{wt} . \%$ of terpolymer inhibitors.

But the double layer capacitance $\left(\mathrm{C}_{\mathrm{dl}}\right)$ value is affected by certain imperfections of the surface, and this effect is simulated via a constant phase element (CPE). The $\mathrm{C}_{\mathrm{dl}}$ value is calculated using the following formula:

$$
\mathrm{CPE}_{d l}=\mathrm{Y}_{o}\left(R c t^{1-n}\right)^{1 / n}
$$

It is worth mentioning that the parameter $\mathrm{n}$ quantifies different physical phenomena like surface in-homogeneities in the form of surface roughness, adsorption of inhibitor, and pores in the adsorbed layer and so on. CPE can correspond to resistor (when $n=0$ ), capacitor (when $n=1$ ), inductor (when $n=-1$ ) and Warburg impedance (when $n=0.5$ ). In this case, $n$ value is close to unity representing that the CPE is a capacitor element [29].

The addition of polymeric inhibitors obviously increased the values of $R_{c t}$ and lowered the values of double layer capacitance. The constant phase elements (CPEs) with their $\mathrm{n}$ values close to unity represent double layer capacitors with some pores [30]. When the value of $n$ ranges between 0.74 and 0.86 , it can be an indication of the charge transfer process controlling the dissolution mechanism [29]. 


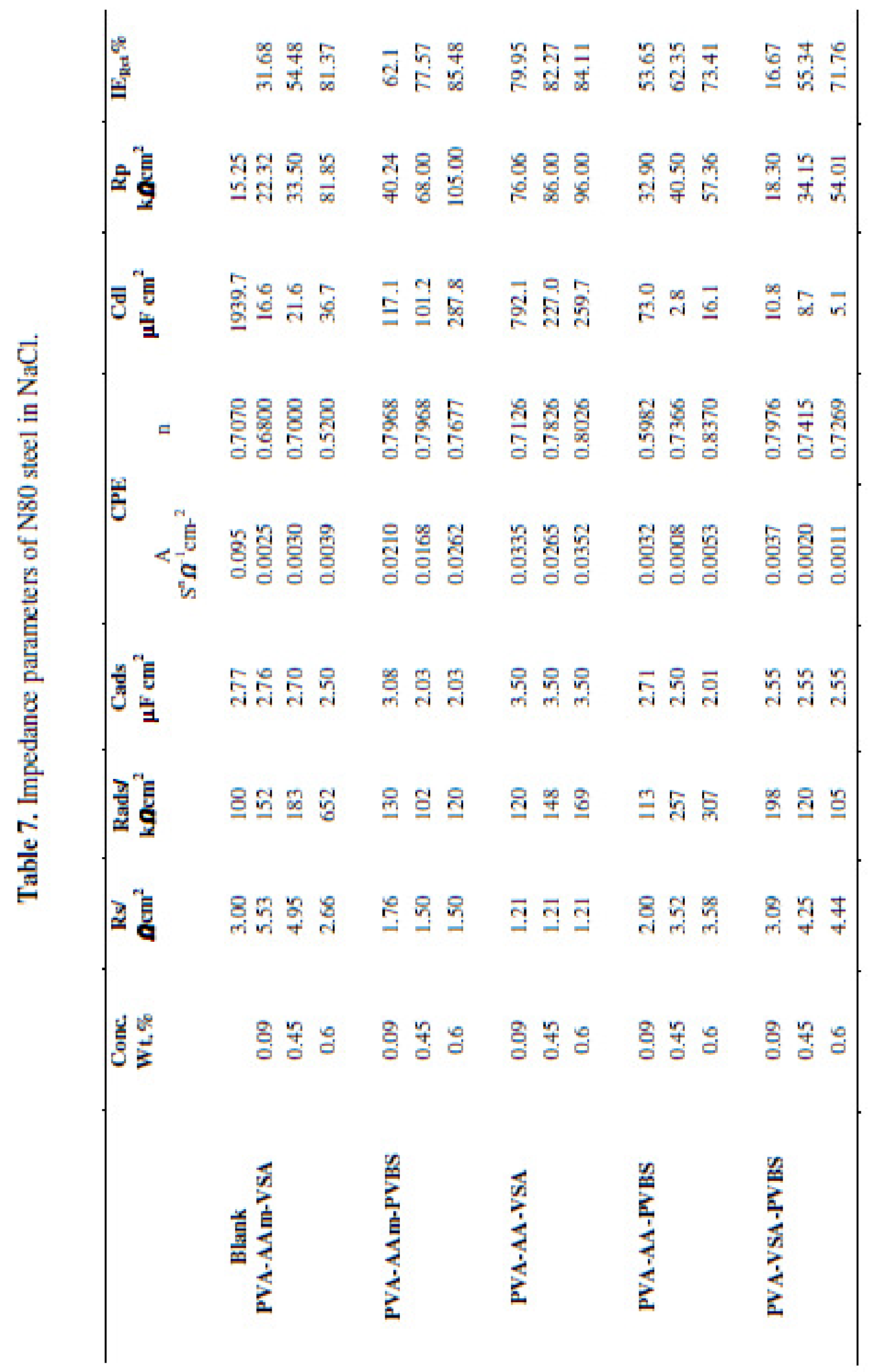




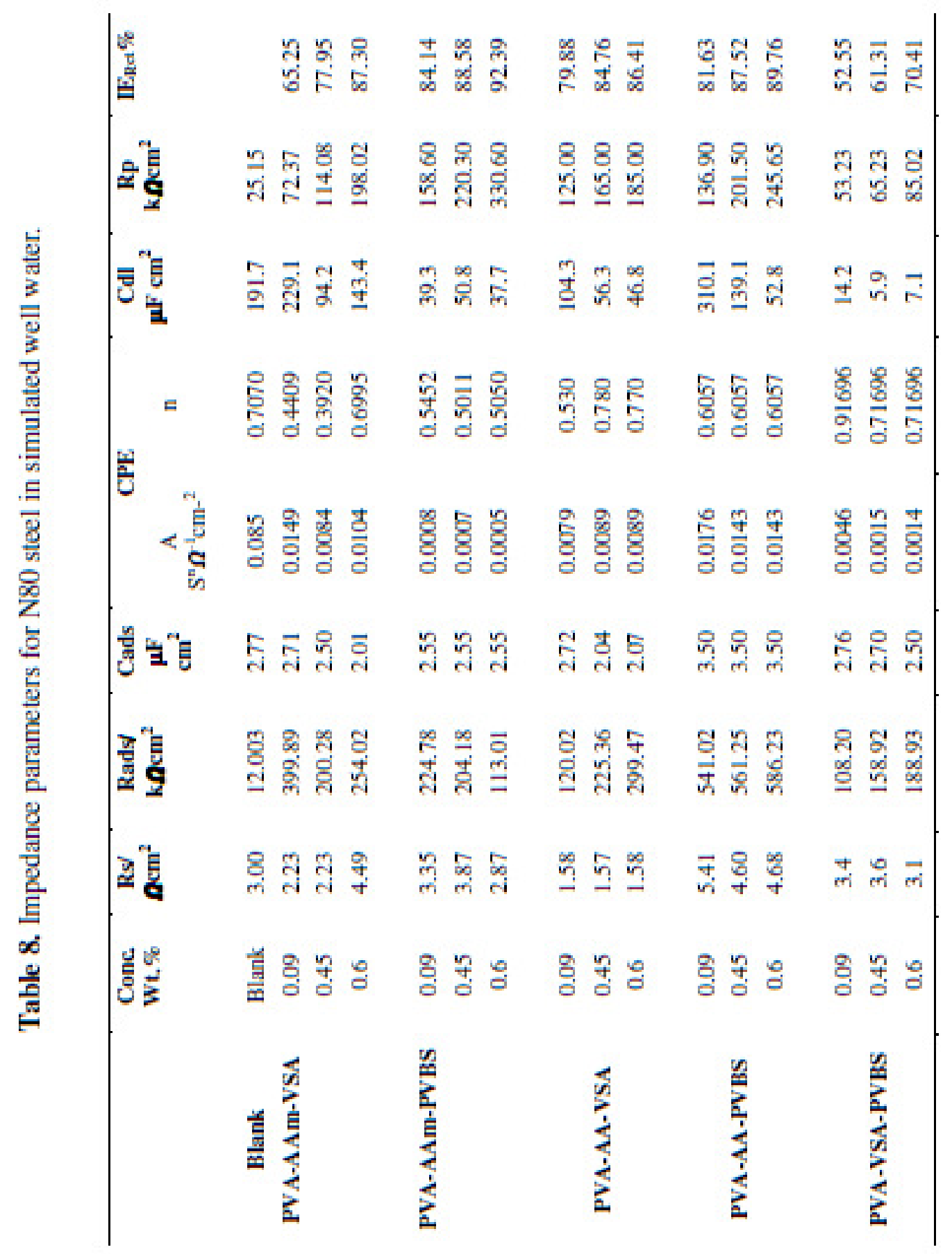

The decrease in CPEs with increase in inhibitor concentrations is expected as an effect of coverage of the charged surfaces and thereby reduction of capacitive effects [31]. Singh et al. 2010 [32] and Bentiss et al. 2000 [33] explain that decrease in $\mathrm{C}_{\mathrm{dl}}$ values is probably an effect of decrease in local dielectric constant and/or an increase in the thickness of the inhibitor layer on metal/solution interface. The decrease in the effective surface area which acts as a place for charging is also a reason for decrease in $\mathrm{C}_{\mathrm{dl}}$. The IE calculated from the $\mathrm{R}_{\mathrm{ct}}$ values shows that maximum IE is rendered by acrylamide terpolymers followed by acrylic acid terpolymers and sulfonate polymers. 


\section{Impedance analysis in $3.5 \% \mathrm{NaCl}$ and simulated oil well water}

Observation of the Figs. 5a-f shows that the diameter of the semicircles is higher (from high frequency to low frequency region) for the inhibited solution when compared to that of the blank solution, indicating the formation of a protective film or reduction in corrosion rate after the addition of inhibitors. The Nyquist plots for $\mathrm{NaCl}$ reflect unduly an elongated semicircle indicating that there is a dispersion of time constants, i.e., the elongated semicircle can be considered as two overlapping semicircles. This high frequency semicircle is associated with the dielectric property of the film whereas the low frequency semicircle is attributed to the diffusion process. The flattened Nyquist plots reveal that there is formation of corrosion products and/or incrustation, hence the corrosion process at the low frequency region can be assumed to be controlled by diffusion [34]. The change in the shape of the impedance plots among the investigated polymers reveals the difference in the protective layer formed by the inhibitors, which is reinforced on the charge transfer surface layer [15]. Various resistances may operate in the neutral corrosion reactions that include charge transfer resistance $R_{c t}$, diffuse layer resistance $R_{d}$, resistance of film $R_{f}$ and resistance created by accumulated species $R_{a}$. The total resistance of the system is taken as $R_{p} ; R_{p}=R_{c t}+$ $R_{d}+R_{a}+R_{f}$. The IE calculated from the $R_{c t}$ values for $0.6 \mathrm{wt} \%$ inhibitor concentration has the following trend: PVA-AAm-PVBS $>$ PVA-AA-VSA $>$ PVAAAm-VSA >PVA-AA-PVBS > PVA-VSA-PVBS.

The Nyquist plot obtained for simulated well water (Fig. 6a-f) shows a straight line at the high frequency region and an unduly elongated semicircle at the low frequency region. The low frequency region in the real axis is attributed to the total resistance, i.e., sum of electronic resistance of the active material, contact resistance with the current collector, and electrolyte resistance. The straight line in the low frequency region is an indication of diffusion-controlled process. The straight lines appear with slopes of $45-90^{\circ}$ indicating diffusive resistance of the electrolyte in electrode pores and the cation diffusion in the host materials [35]. The slope of the straight line is larger for the inhibitor added solution when compared with that of blank simulated well water solution which denotes a lower diffusive resistance of the electrode after inhibitor addition.

The circuit used for fitting $\mathrm{NaCl} /$ simulated well water contains elements that can be described as follows: $R_{\text {ads }} / C_{\text {ads }}$ is the high frequency time constant attributed to the adsorption of the inhibitor and $R_{\mathrm{p}} / C_{\mathrm{dl}}$ is the low frequency time constant attributed to the defect sites where charge transfer processes take place $[15,21]$. This situation arises when the charge transfer resistance for anion exchange is larger than the relaxation of cations at the surface of the film [36]. The data presented in Tables 7 and 8 reveal that progressive addition of polymeric inhibitors obviously increased the values of $R_{p}$ and inhibition efficiency calculated from $R_{p}$ and lowered the values of double layer capacitance corresponding to the high-frequency semicircle. The decrease in Cdl values is due to the adsorption of the inhibitor on the electrode surface. The IE rendered by the terpolymers in simulated oil well water was found to follow the same trend as that of $\mathrm{HCl}$ medium. 


\section{Weight loss}

The persistency of the inhibitor action is a vital aspect in assessing the efficiency of an inhibitor. During the application of inhibitors in oil and gas wells and flowlines, continuous supply of an inhibitor may not be possible. When the inhibitor is applied at a low concentration continuously it is cumbersome to meet the adequate requirement throughout the pipeline [37]. Hence, persistency of inhibitive action can therefore be considered as a primary criterion for evaluation of inhibitors, and in the present study it is carried out under static and dynamic conditions by weight loss method. From the electrochemical studies, it can be observed that a maximum inhibition efficiency (IE) was obtained for the highest concentration $(0.6 \mathrm{wt} . \%)$ of the inhibitors under investigation. Hence $0.6 \mathrm{wt} . \%$ was fixed as optimum inhibitor concentration and further evaluation of corrosion protection efficiency was carried out under static and dynamic conditions. Table 7 collects the IE obtained for five grafted terpolymers on N80 steel under static and dynamic conditions. The values of IE obtained under static conditions are lesser than that obtained for dynamic conditions. This can be attributed to the following reasons:

1. The easy adsorption of inhibitor molecules on the metal surface even in short contact time, i.e., in dynamic conditions the metal comes in contact with the inhibitor solution in gradual intervals during each rotation.

2. The splashing force of the inhibitor solution could have also helped the adsorption of the inhibitors.

3. The persistency of the adsorbed molecules on the surface which also shows the chemisorption of the inhibitor molecules.

As far as the corrosive media are concerned, the inhibitors were found to work well in simulated well water followed by $\mathrm{HCl}$ and $\mathrm{NaCl}$. Sulphuric acid is formed in simulated well water by reaction of $\mathrm{H}_{2} \mathrm{~S}$ with the dissolved oxygen. The sulphur-containing compounds generally work well in sulphuric acid medium thus imparting a highest efficiency [38, 39]. All the inhibitors under investigation contain sulphur which could have contributed to the highest inhibition in simulated well water. The highest efficiency is however observed for inhibitors containing acrylamide along with sulfonate. The inhibition efficiency is slightly reduced in $\mathrm{HCl}$ medium. In $\mathrm{HCl}$ medium the adsorption of inhibitors predominantly occurs through electrostatic interaction with the chloride ions on the metal surface. This electrostatic interaction could have been reduced at the studied temperature $\left(60{ }^{\circ} \mathrm{C}\right)$. In $3.5 \% \mathrm{NaCl}$ solution, due to weak electrostatic interactions, the inhibition efficiency is smaller than the others. From these observations, the inhibition efficiency of the terpolymers can be related to the hetero atom population and their interaction with the metal which will be discussed in detail the forthcoming section.

\section{Mechanism}

The adsorption process is affected by many factors including chemical structure of the inhibitor, hetero atom population, total charges present and their distribution over the inhibitor molecule. A corrosion inhibitor actually functions 
by reacting with the metal ion that is newly produced in the corrosive medium, but in a plane very near or on the metal surface [40]. The adsorption can be physical or chemical in nature. Four types of adsorption may take place by the inhibitor molecules at the metal-solution interface [41]:

- electrostatic attraction between the charged molecules and the charged metal;

- interaction of uncharged electron pairs in the molecule with the metal;

- interaction of p electrons with the metal, and

- combination of 1 and 3 .

As far as the metal surface is considered, it undergoes following types of reactions in different corrosive media. The anodic reaction of iron in $\mathrm{HCl}$ is given by Solamaz et al. (2011) [42].

$$
\begin{aligned}
& \mathrm{Fe}+\mathrm{Cl}^{-} \leftrightarrow\left(\mathrm{FeCl}^{-}\right)_{\text {ads }} \\
& (\mathrm{FeCl})_{\text {ads }} \leftrightarrow(\mathrm{FeCl})_{\text {ads }}+\mathrm{e}- \\
& (\mathrm{FeCl})_{\text {ads }} \leftrightarrow \mathrm{FeCl}++\mathrm{e}^{-} \\
& \mathrm{FeCl}+\leftrightarrow \mathrm{Fe}^{2+}+\mathrm{Cl}^{-}
\end{aligned}
$$

The cathodic hydrogen dissolution is given as follows

$$
\begin{aligned}
& \mathrm{Fe}+\mathrm{H}^{+} \leftrightarrow\left(\mathrm{FeH}^{+}\right)_{\text {ads }} \\
& \left(\mathrm{FeH}^{+}\right)_{\mathrm{ads}}+\mathrm{e}-\leftrightarrow(\mathrm{FeH})_{\mathrm{ads}} \\
& (\mathrm{FeH})_{\text {ads }}+\mathrm{H}++\mathrm{e}-\leftrightarrow \mathrm{Fe}+\mathrm{H}_{2} \text { (hydrogen evolution) }
\end{aligned}
$$

The corrosion of iron in neutral or saline media is given as [43,44]:

$$
\begin{aligned}
& \mathrm{Fe} \rightarrow \mathrm{Fe}^{2+}+2 \text { e- } \\
& \mathrm{Fe}^{2+} \rightarrow \mathrm{Fe}^{3+}+\mathrm{e}- \\
& \mathrm{Fe}+\mathrm{Cl}^{-} \rightarrow \mathrm{FeCl}+\mathrm{e}- \\
& \mathrm{FeCl}+\mathrm{Cl}^{-} \rightarrow \mathrm{FeCl}_{2}^{-}+\mathrm{e}-
\end{aligned}
$$

Meanwhile, iron develops oxide layers that partially protect the surface being attacked by chloride ions. It was also found that iron could develop nine different types of oxide phases on their surfaces. The oxide formation occurs according to the following equations

$$
\begin{aligned}
& \mathrm{Fe}+1 / 2 \mathrm{O}_{2}+\mathrm{H}_{2} \mathrm{O} \rightarrow \mathrm{Fe}(\mathrm{OH})_{2} \\
& 3 \mathrm{Fe}(\mathrm{OH})_{2}+1 / 2 \mathrm{O}_{2} \rightarrow \mathrm{Fe}_{3} \mathrm{O}_{4}+3 \mathrm{H}_{2} \mathrm{O}
\end{aligned}
$$

The chemical reaction proposed for iron dissolution in neutral media containing hydrogen sulphide is shown below.

$$
\mathrm{Fe}+\mathrm{H}_{2} \mathrm{~S} \rightarrow \mathrm{FeS}+\mathrm{H}_{2}
$$

It is also assumed that iron dissolution does not occur immediately, before which a fast oxidation of solid iron occurs and transforms directly into iron sulphide. Then the iron sulphide is strongly adhered on the metal surface, but still this mechanism is under question including the role of various factors that influence the formation of different types of sulphide products.

The terpolymer under investigation has electron rich centres that aid in adsorption of the inhibitors, as given in Fig. 7. In the present study, 
polyacrylamide (cationic) polymeric inhibitors probably adsorb by electrostatic interaction between the positively charged nitrogen atom $\left(\mathrm{N}^{+}\right)$and the negatively charged metal surface. The metal surface becomes negative charged due to the adsorption of chloride ions from $\mathrm{HCl} / \mathrm{NaCl}$ and $\mathrm{HS}^{-}$ions from simulated well water. This prevents any $\mathrm{H}^{+}$getting nearer to the metal surface $[45,46]$. The $\mathrm{COO}^{-}$anions of polyacrylic acid polymers, and $\mathrm{SO}_{3}{ }^{-}$anions of sulfonate polymers electrostatically form linkages with the positive sites of the metal. All the investigated polymers have hydrophilic segments in which the lone electron pairs of the oxygen atoms form coordinate bonds with the empty orbitals of iron atoms. The inhibitive effect can also be due to the formation of bonds between the empty d-orbital of iron atoms and the lone pair of electrons present in the $\mathrm{N}$, $\mathrm{O}$ and $\mathrm{S}$ atoms of the whole terpolymer $[47,48]$. The protective ability of the sulphur compounds is governed by the fact of greater polarization of $\mathrm{C}-\mathrm{S}$ bonds [49].

The PVBS polymers also get attracted to the metal surface through the $\pi$ electrons on the benzene ring. While the $\pi$ orbital of the inhibitor molecule donates electrons to the empty orbital of the metal atom, there is also possibility of $\pi^{*}$ orbital to accept electrons from the metal orbital thereby forming feedback bonds [50].

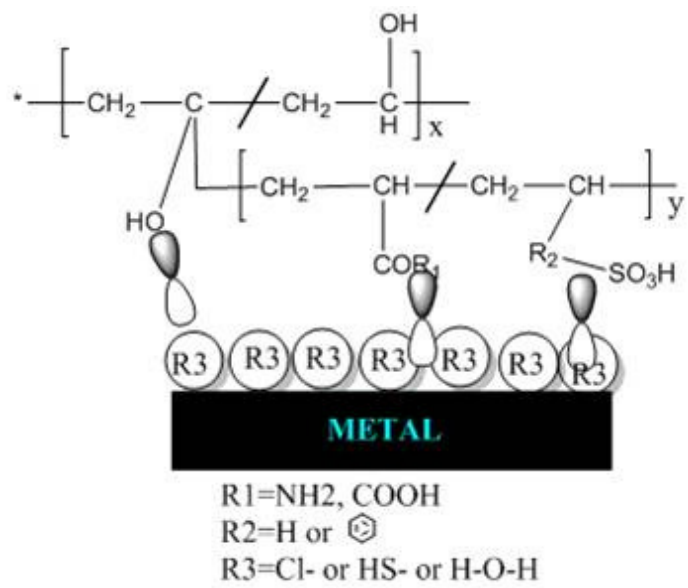

Figure 7. Plausible mechanism of inhibition on N80 steel in the investigated systems by terpolymers.

A hydrophobic, dense and defect-free monolayer is formed by the neighbouring alkyl chains through van der Walls' forces, which acts as a barrier between the metal surface and the corrosive environment, thereby protecting the iron surface from corrosion $[51,52]$. It is worth mentioning the metal chelating property of the polychelatogen poly(acrylic acid-co-vinyl sulfonic acid) discussed by Rivas et al. (2003) [52], which further supports the inhibitive mechanism of polyacrylic acid containing terpolymers through complex formation. These complexes might be adsorbed on the steel surface through van der Walls' forces and forms a barrier layer to prevent from corrosion. Depending upon the population of hetero atoms, pi bonds, unshared electron pair and electrostatic charges, the order of inhibition of the terpolymers obtained in different techniques is well in agreement with the order as shown below. 
PVA-AAm-PVBS $(\mathrm{O}+\mathrm{N}+\mathrm{S}+$ phenl moiety) $>$ PVA-AAm-VSA $(\mathrm{O}+\mathrm{N}+\mathrm{S})>\mathrm{PVA}-$ AA-PVBS $(\mathrm{O}+\mathrm{S}+$ phenyl moiety) $>$ PVA-AA-VSA $(\mathrm{O}+\mathrm{S})>$ PVA-VSA-PVBS $(\mathrm{O}+\mathrm{S}+$ phenyl moiety).

\section{Conclusions}

Among the five terpolymers investigated, acrylamide terpolymers were found to be effective in controlling the corrosion of different media. The potentiodynamic polarisation study shows that the corrosion currents are minimized by the addition of the inhibitor. The IE was well pronounced in simulated oil well water followed by $\mathrm{HCl}$ and $3.5 \% \mathrm{NaCl}$. The inhibitors action persistency analysed by static and dynamic weight loss method shows that the inhibitor action is persistent in dynamic conditions (Table 9). Hence the inhibitors can be optimized and recommended for usage in oil wells containing sour corrosion problems.

Table 9. Comparative results of IE obtained for the different polymers in static, dynamic and potentiodynamic techniques.

\begin{tabular}{lcccccc}
\hline & \multicolumn{2}{c}{ HCl } & \multicolumn{2}{c}{ NaCl } & \multicolumn{2}{c}{ NaCl + H2S } \\
Blank & Static & Dynamic & Static & Dynamic & Static & Dynamic \\
PVA-AAm-VSA & 72.3 & 75.52 & 72.39 & 74.26 & 79.56 & 86.61 \\
PVA-AAm-PVBS & 74.36 & 76.80 & 71.87 & 74.85 & 78.54 & 82.52 \\
PVA-AA-VSA & 70.25 & 75.12 & 68.25 & 71.70 & 69.36 & 72.33 \\
PVA-AA-PVBS & 72.36 & 74.62 & 70.14 & 72.02 & 75.45 & 79.62 \\
PVA-VSA-PVBS & 69.75 & 75.73 & 65.25 & 67.77 & 68.55 & 72.71 \\
& & & & & & \\
\hline
\end{tabular}

\section{Acknowledgement}

One of the authors, Geethanjali. R, thanks 'Tamil Nadu state council for science and technology, Government of TamilNadu' for catalyzing and financially supporting the research work, and R\&D labs of IOGPT and RRL of ONGC Mumbai, for carrying out dynamic studies.

\section{References}

1. Williams DA, Holifield PK, Looney JR, et al. US Patent 5209859. 1993.

2. Baddini SP, Cardoso E, Hollauer JÁ, et al. Electrochim Acta. 2007;53:434.

3. Sherif ESM. Ind Eng Chem Res. 2013;52:14507.

4. Quraishi MA, Jamal D. 2001;71:202.

5. Haldar N, Shukla HS, Udhayabhanu G. Ind J Chem Technol. 2012;19:173.

6. $\quad$ Prakash D, Singh RK, Kumari R. Ind J Chem Technol. 2006;13:555.

7. Amosa MK, Mohammed IA, Yaro SA, et al. NAFTA. 2010;61:239.

8. Khaled KF, Int J Electrochem Sci. 2008;8:462.

9. Growcock FB, Lopp UR. Corros Sci. 1988;28:397.

10. Zeng H, Zhao SX, Li YW. Corrosion inhibition and antibacterial effects of copolymer NIPAM-co-BPCP on N80 steel panel. Academy of life science and chemistry, Xinjiang Normal University, Urumugi-830054; 2009.

11. Okafor PC, Liu CB, Liu X., et al. J Solid State Electrochem. 2009;14:1367.

12. Finšgar M, Fassbender S, Hirth S et al. Mater Chem Phys. 2009;116:198.

13. Finšgar M, Fassbender S, Nicolini F, et al. Corros Sci. 2009;51:525.

14. Gao J, Weng Y, Salitanate S, et al. Petrol Sci. 2009;6:201. 
15. Azghandi MV, Davoodi A, Farzi GA, et al. Corros Sci. 2012;64:44.

16. Bentiss F, Jama C, Mernari B, et al. Corros Sci. 2009;51:1628.

17. Azghandi MV, Davoodi A, Farzi GA, et al. Metallurgical Mater Trans A. 2013;44:5493.

18. Tao Z, Zhang S, Li W, et al. Corros Sci. 2009;51:2588.

19. Zhang G, Chena C, Lub M, et al. Mater Chem Phys. 2007;105:331.

20. Arora A, Pandey SK. SPE International, SPE. 2012;155211:1.

21. Geethanjali R, Sabirneeza AAF, Subhashini S. Ind J Mat Sci. 2014;Article ID 356075:1-9.

22. Amin MA, EI-Rehim SSA, El-Sherbini EEF, et al. Corros Sci. 2009;51:658.

23. Alhajj JN, Reda MR. Corros Sci. 1993;34:1899.

24. Khaled KF. Corros Sci. 2010;52:2905.

25. Rahmouni K, Keddam M, Srhiri A, et al. Corros Sci. 2005;47:3249.

26. Vishwanatham S, Haldar N. Corros Sci. 2008;50:2999.

27. Ostovari A, Hoseinieh SM, Peikari M, et al. Corros Sci. 2009;51:1935.

28. Rosliza R, Wan Nik WB, Senin HB. Mater Chem Phys. 2008;107:281.

29. Wanying L, Ambrish S, Yuanhua L, et al. Int J Electrochem Sci. 2014;9:5574.

30. Sherif EM, Park S-M. Corros Sci. 2006;48:4065.

31. Khaled KF. Mater Chem Phy. 2008;112:104.

32. Singh AK, Quraishi MA. Corros Sci. 2010;52:152-160.

33. Bentiss F, Traisnel M, Lagrenee M. Corros Sci. 2000;42:127.

34. Perez EJ, Cabrera-Sierra R, González I, et al. Corros Sci. 2007;49:3580.

35. Feliu S, Galvan JC, Feliu Jr S. et al. Corros Sci. 1993;35:1351.

36. Venugopal A, Raja VS. Corros Sci. 1997;39:2053.

37. Tan YJ, Bailey S, Kinsella B. Corros Sci. 1996;38:1545.

38. Loto RT, Loto CA, Popoola API. J Mater Env Sci. 2012;3:885.

39. Shen CB, Wang SG, Yang HY, et al. Corros Sci. 2006;48:1655.

40. Ebenso EE, Ekpe UJ, Ita BI, et al. Mater Chem Phys. 1999;60:79.

41. Shokry H, Yuasa M, Sekine I, et al. Corros Sci. 1998;40:2173.

42. Solmaz R, Altunbaş E, Kardaş G. Mater Chem Phy. 2011;125:796.

43. Sherif E-SM, Erasmus RM, Comins JD. Electrochim Acta. 2010;55:3657.

44. Sherif E-SM. Ind Eng Chem Res. 2013;52:14507.

45. Shen CB, Wang SG, Yang HY, et al. Corros Sci. 2006;48:1655.

46. Migahed MA, Mohamed HM, Al-Sabagh AM. Mater Chem Phy. 2003;80:169.

47. Chandra BV, Quraishi MA, Ebenso EE. Int J Electrochem Sci. 2014;9:5537.

48. Appa Rao BV, Iqbal YM, Sreedhar B. Corros Sci. 2009;51:1441.

49. Oguzie EE. Mater Chem Phys. 2004;87:212.

50. Behpour M, Ghoreishi SM, Soltani N, et al. Corros Sci. 2008;50:2172.

51. Y Ren Y, Luo Y, Zhang K, et al. Corros Sci. 2008;50:3147.

52. Rivas BL, Nicolas SL. J App Polym Sci. 2003;88:1698. 